\title{
Semiotics Analysis of Food and Beverages Billboards in Hyderabad, Sindh
}

\author{
Anum Hussain \\ MS. Scholar, Mehran University of Engineering \& Technology, Jamshoro \\ Dr. Habibullah Pathan \\ Associate Professor, Mehran University of Engineering \& Technology, Jamshoro \\ Syed Waqar Ali Shah \\ Lecturer, Mehran University of Engineering \& Technology, Jamshoro
}

\begin{abstract}
Advertisement is one of the vital part of our daily lives. Advertisements are of the various types but the billboards are common and omnipresent. The billboards are categorized under outdoor advertisement. This study is conducted in the context of Hyderabad, Sindh. The researcher has analyzed food and beverages billboards under the theory of Barthes' semiology. The scholar has analyzed the data under the first and second order of Roland Barthes' theory. The denotation and connotation meaning have been analysed. The researcher has used qualitative methodology. The results show that advertisers used various linguistic sign, colors and images in order to manipulate the audiences to sell their product.
\end{abstract}

Keywords:billboards, semiotics, Hyderabad, Roland Bathes

DOI: $10.7176 /$ JLLL/81-01

Publication date:August $31^{\text {st }} 2021$

\section{CHAPTER 1}

\section{INTRODUCTION}

\subsection{Background of the study}

In this modern era, advertising is the basic means of communication between the entrepreneur and consumers. According to Cook (2001), Advertisement is found everywhere in the world, it has formed a new culture that overlooks the coast-to-coast restrictions. Not all the people have enough time to sit in front of television and enjoy the day because of their busy schedule; they fail to keep up to date with the new products. Therefore, the advertisers put forward the outdoor advertisement which helps the public to get knowledge about products, among outdoor advertisement billboards are considered most useful and cheap as compare to other modes of advertisement. Billboards advertisement is cheaper than television commercials.

Bignell (2002) claims that the print media portrays the message with the usage of color, sign and intertextuality which is a source to beautify the advertisement the companies and product owners want to sell their products as quickly as it could be therefore, they advertise their products and wants to gain the attention of the viewers. And to get attention the advertisers use various colors, pictures and text in order to sell their products.

Billboard advertisement is a direct way of communication between advertiser and audience. It is a direct way of communication between advertiser and audience. The effective billboard requires the easy to perceive and brief message, appealing demonstration and visual outlook. Billboard advertising has become a fast and convenient way to promote businesses in Hyderabad and other cities.

Adams et al. (2014) claims that the intention of the advertiser is to give connotations to the consumers of the product by designing relations in the mind of the audience so that the consumers can relate to it and buy the productThere is one limitation of the billboard advertising that it takes couple of seconds to audience to view the advertisement. In order to get over with this limitation the advertisers choose its solution by using the limited words for the billboard advertising. The ideal number of words which are used in the billboard to convey the proper is six words.

This study deals with the analysis of food and beverages billboards under the light of Barthes' semiology. The billboards are collected from the context of Hyderabad, Sindh. The billboards have been analysed under the theory of semiology. This study is analyzed under the light of qualitative method. Chauhan (2012) maintains that qualitative research attempts to understand the meanings that people give to their deeds and social phenomenon. The present study is qualitative as it follows all notions of qualitative research and its main characteristics.

\subsection{Research Problem}

Billboards advertisement is one of the most used outdoor advertisement in the present era. It conveys messages which are exposed to the large amount of audience on daily basis. These messages are verbal and non-verbal 
both and affect the consumers. Therefore, this study evaluates semantic, Symbolic and cultural codes under the light of semiology of Ronald Barthes.

\subsection{Aims and Objectives}

The study aims to investigate the meaning behind the billboards of food and beverages in terms of connotation and denotation level of Barthes.

- To investigate the literal meaning of the billboards of food and beverages brands in Hyderabad.

- To analyze the cultural implication behind the billboards of food and beverages brands in Hyderabad.

- To evaluate the semantic, symbolic, and cultural codes in the billboards advertisement of food and beverages brands in Hyderabad.

\subsection{Research Questions}

- Which meaning is conveyed through the images of billboards of the food and beverages brands in Hyderabad?

- Which cultural implications are portrayed in the advertisement of billboards of the food, and beverages brands in Hyderabad?

- Which codes of Barthes are used in the billboards of the food, and beverages brands in Hyderabad?

\section{LITERATURE REVIEW}

\subsection{Related Literature}

Da'Silva. (2017), analysed the tea billboard advertisement in Jakarta. The scholar wants to investigate into the non-linguistics and linguistics features of an old brand of green tea in Jakarta, Indonesia. The results show that all the billboards relation between the colors, non-human object, composition and most importantly, the use of language is very selective which pursue the audience towards the product.

Ridho Yanti and Rina (2019) analyzed the meaning behind slogans of trending cigarettes' billboards of Dunhill Filter and Sampoerna. The scholars examined the implied meaning behind the slogans of billboards of cigarettes including that the role of context in advertising is also explored. The results show that the cigarette brands target the particular audience with the help of persuasive slogans. In addition to that the advertisers also play with the words in terms of situation. Language connotation varies from context to context. The context reveals the real meaning of the slogans. Hence, the advertisers use the contextual elements to manipulate the audience to sell their product.

Pramudita, Susilo and Rohayanti (2019) have analyzed the signs and meanings used in advertisement of Sariayu hijab care under the light of semiotics. The researchers have used the semiotics theory of Ronald Barthes and Commodification Theoretical Concept. Scholars have selected 6 explicit advertisements from social media account and the researchers alleged that by highlighting the word "hijab" the advertisers want to interwoven the brand products with religion and the green color is majorly used in the advertisements which shows the products are of natural herbs.

Ma'rifah (2020), have conducted the research on the children's perceptions on the food advertisement. The study was done under the light of semiotics. The researcher interviewed the children of 8 to 10 years old. The scholar claimed that young children were able to understand the advertisements and its messages. However, the children suggested to add more cartoon characters in advertisements.

Wibowo and Ardhianto, (2020) have conducted the research and explored the billboards of Go-Jek advertisements. The study focused on the analysis of icons that are used in the advertisement. The results show that the major focus of the company is to convince the audience to order food online rather than go out to buy food. The company uses the slogan "Lazy to move" which convinces consumers to order food not to go out.

\section{RESEARCH METHODOLOGY}

\subsection{Research Design}

The descriptive qualitative analysis has been used to analyze the data. According to Nassaji (2015), descriptive research is often used as an antecedent to quantitative research designs; it represents the general view proposed to give some valuable instruction about which variables are worth trying quantitatively.

\subsection{Sampling}

The researcher has done random sampling in order to analyze data. 6 billboards of various food and beverages brands have been analyzed. The pictures of the billboards are captured by the researcher personally from different areas of Hyderabad. 


\begin{tabular}{|l|c|}
\hline Number & Food and Beverages Brands \\
\hline $\mathbf{1}$ & 7up \\
\hline $\mathbf{2}$ & Lays \\
\hline $\mathbf{3}$ & Dairy Milk \\
\hline $\mathbf{4}$ & Pizza Track \\
\hline $\mathbf{5}$ & Burger House \\
\hline $\mathbf{6}$ & Pizza Hut \\
\hline
\end{tabular}

\subsection{Data collection tools and techniques}

The data in this article is collected through both primary and secondary sources under the light of the qualitative method. A quantitative study was suitable in this study which seeks to investigate the meaning which is conveyed in the billboard advertisement of food and beverages.

\subsection{Research Framework: Ronald Barthes' Semiology}

Ronald Barthes is considered the leading semiotician. He is following the approach of semiotics by Saussure. Barthes believes the sign is the form of either text or context. He presented two orders of signification that give meaning to the text or speech. And these meanings are evaluated under two levels: denotation and connotation. Denotation is the reality of the sign however, at the connotation level sign is analyzed in the light of culture.

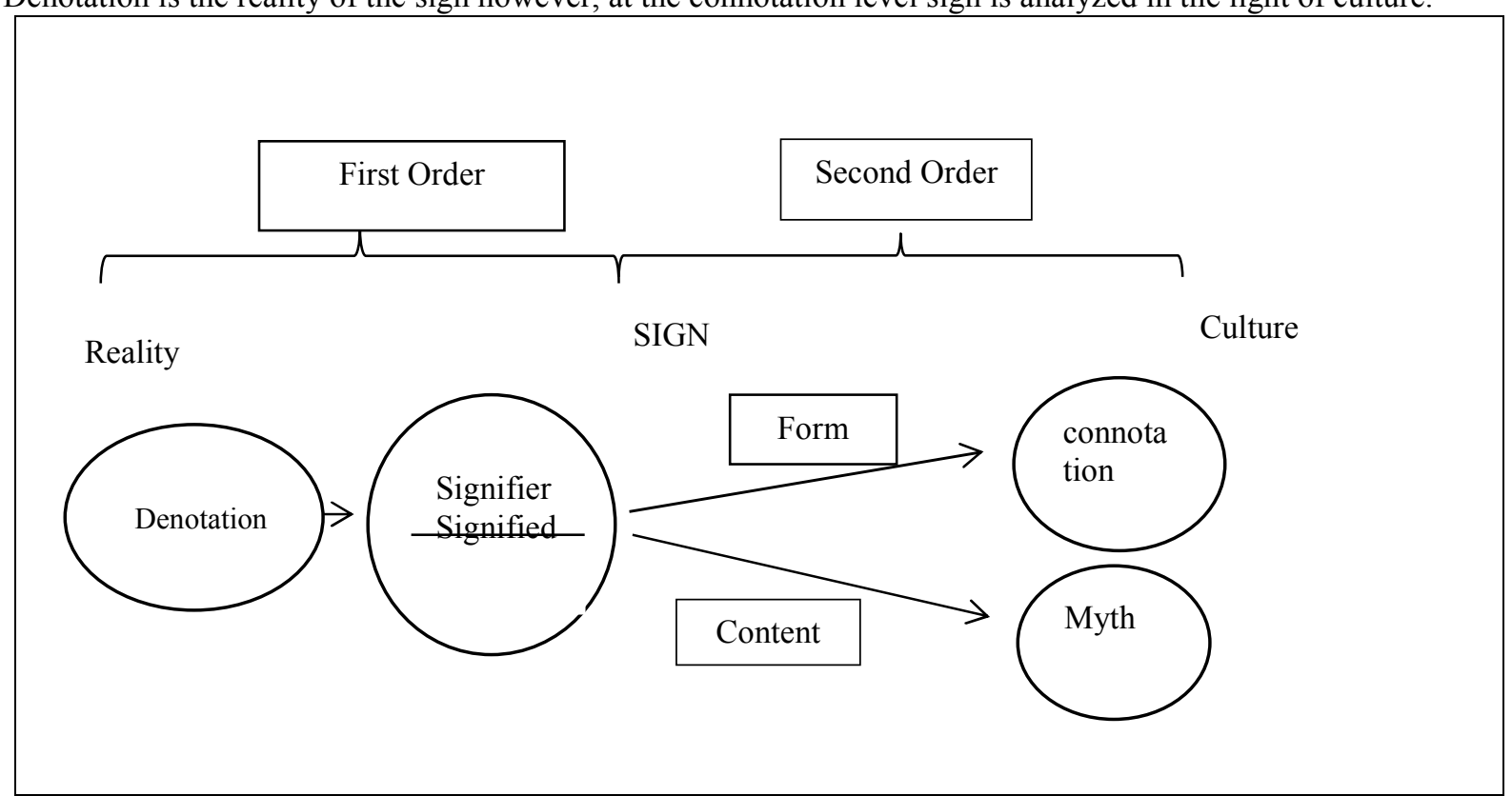

Figure: 2 John Fiske, Introduction to Communication studies, 1990.p.88.

Ronald Barthes' first order highlights the relation between the signifier and signified which forms the external reality; Barthes named the first order as denotation. At the denotation level, the sign is analyzed as the literal it conveys the real meaning. However, the term connotation has the association of ideological and sociocultural of the sign. The sign is interpreted under the light of its culture, trends, ideologies, etc.

Along with the denotation and connotation aspect of the sign, Barthes has put forwarded the codes of signification. The cultural members share the codes as the meaning system. The signs are linked with codes. Basically, the code is a way to interpret possible meanings in terms of a particular society and its culture. Through the various codes meaning of connotation could be interpreted. The codes of the second-order signification are defined below:

- Hermeneutic Code: This is a very effective code in various ways. It has a tendency to work in different ways. Under the light of this code, a text can be questioned, answered, interpreted, or make the meaning remain hidden. It can construct the mystery also it can lead to the solution.

- Proairetic Code: It is also known as the "code of actions" it enriches the suspense among the readers.

- Semantic Code: This is code that relates to connotation. It helps to evaluate the text on a deep level. It gives additional meaning to the text. Semantic code can unveil the hidden meaning.

- $\quad$ Symbolic Code: This code is termed as antithetic code. This code is related to semantic code but it organizes semantic meanings. Barthes did not clearly differentiate semantic and symbolic code.

- Cultural Code: It is also known as referential code. By this code, Barthes refers to the text with the society and culture. It gives the socio-cultural meaning to the text. 
In this study, the researcher has evaluated the billboards under the light of denotative meaning, and among connotative meaning, three codes would be used: Semantic code, symbolic code, and cultural code. Because the ideal text on the billboards is six words, therefore, the first two codes could not be applicable for billboards analysis.

\section{FINDINGS AND DISCUSSION}

This chapter deals with the analysis of the billboards of Food and beverages. As the data is analysed under the theory of semiotic signification by Barthes applied on the billboards in the context of Hyderabad, Sindh.

\subsection{Food and Beverages.}

Lays

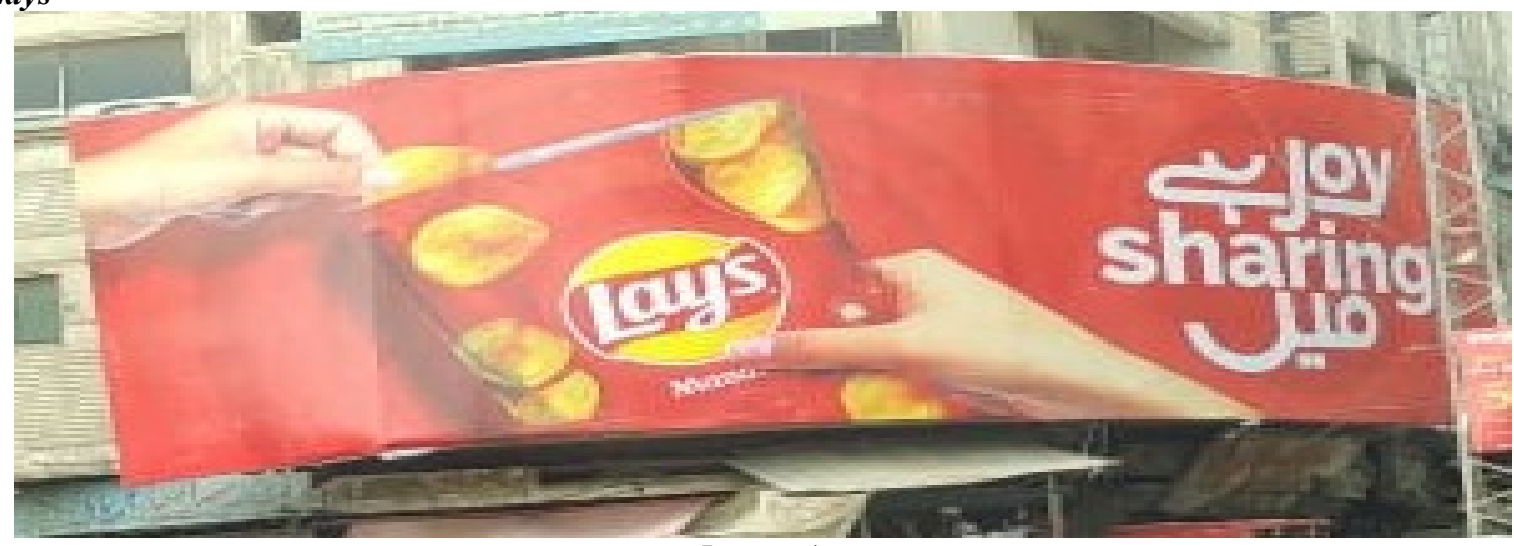

Image: 1

\begin{tabular}{|c|c|c|}
\hline SIGN & $1^{\text {st }}$ Order Signification & $2^{\text {nd }}$ Order Signification \\
\hline $\begin{array}{ll}\text { - } & \text { Chips } \\
\text { - } & \text { Hands }\end{array}$ & $\begin{array}{l}\text { - } \\
\text { - } \quad \text { Hands sharing the chips. } \\
\text { - } \quad \text { Red color theme and } \\
\text { white text. }\end{array}$ & $\begin{array}{l}\text { - Code mixing, use of English and Urdu. } \\
\text { - } \quad \text { Targeting larger audience } \\
\text { Delimiting gender by sharing the product. } \\
\text { - Sharing makes people Happy }\end{array}$ \\
\hline
\end{tabular}

Table: 1

\section{Denotation meaning}

In the billboard of lays the viewers can clearly see the red background of the billboard with white text on it, which are only four words, the text is written in Urdu and English Languages. The red color of the billboard is recognized as signifier because it is complementing the product which is red in color. The text on the billboards is identified as the signifier which is written on the right side of the billboard. In the text the motto of sharing is promoted, similar concept is displayed in the image or picture which is shown on the billboard. In the picture, two hands are shown one hand which is of the female is sharing the "Masala Lays Flavour" with the male.

\section{Connotation meaning.}

According to intermedia, colors can be considered as meaningful and psychological. Colors plays important role in the billboard's advertisement. Singh (2006), is of the view that colors affects the consumers' mood, feeling and differentiating products. He further added that around 62-90\% people decide to buy the product by selection of the color. Therefore, the selection of color in terms of designing the billboard is very much important. As it affects the choice of the consumer.

The red color is not only identified as signifier but it also has underline meaning which is classified under the category of signified. The red color in advertisements is used in order to grab attention of the audiences. The color of the product "Lays" is also red. Which is the representation of the desire. therefore, the packet of chips is the desire of people. The white color is representing the purity of the product. In addition to that, yellow color can also be seen in the picture. The chips are of the yellow color, which can be seen in the packet of the chips, and in the logo. The yellow color shows the happiness and good times which is supporting the slogan in the billboard.

The number of words on the billboards are four but these four words are conveying the great message of sharing. Two languages are used in the billboards. The two languages have cultural association with the nation. Urdu which is national language of Pakistan and the second language which is used in the billboard is English. As English is considered as official language but it is used by masses in daily life, it is also used as medium of 
instructions in many private institutes. Therefore, the codeswitching is targeting the youth of the nation, which used both languages simultaneously. This code-mixing phenomenon is supporting the motto of the billboard which is sharing. The two languages are sharing words in order to give meaning.

Boterill et al. (2000), cited Barthes, he claims that advertisements are designed with certain strategies which usually use idealistic concepts in order to attach desired notion with the product. Similarly, the hands in the billboard are conveying the symbolic meaning of sharing which brings happiness to the life. In addition to that, the hands in the picture are delimiting the genders. The brand has conveyed through "hands" that any gender can have their product and share with the happiness to enjoy the life. Dunbar (2017) conducted the research on eating food with others and the results show the people who eat food together make the people happy and satisfied. Therefore, the motif of Lays Billboard advertisement is to share the product which bring happiness. The motif of the brand is to share Lays with others.

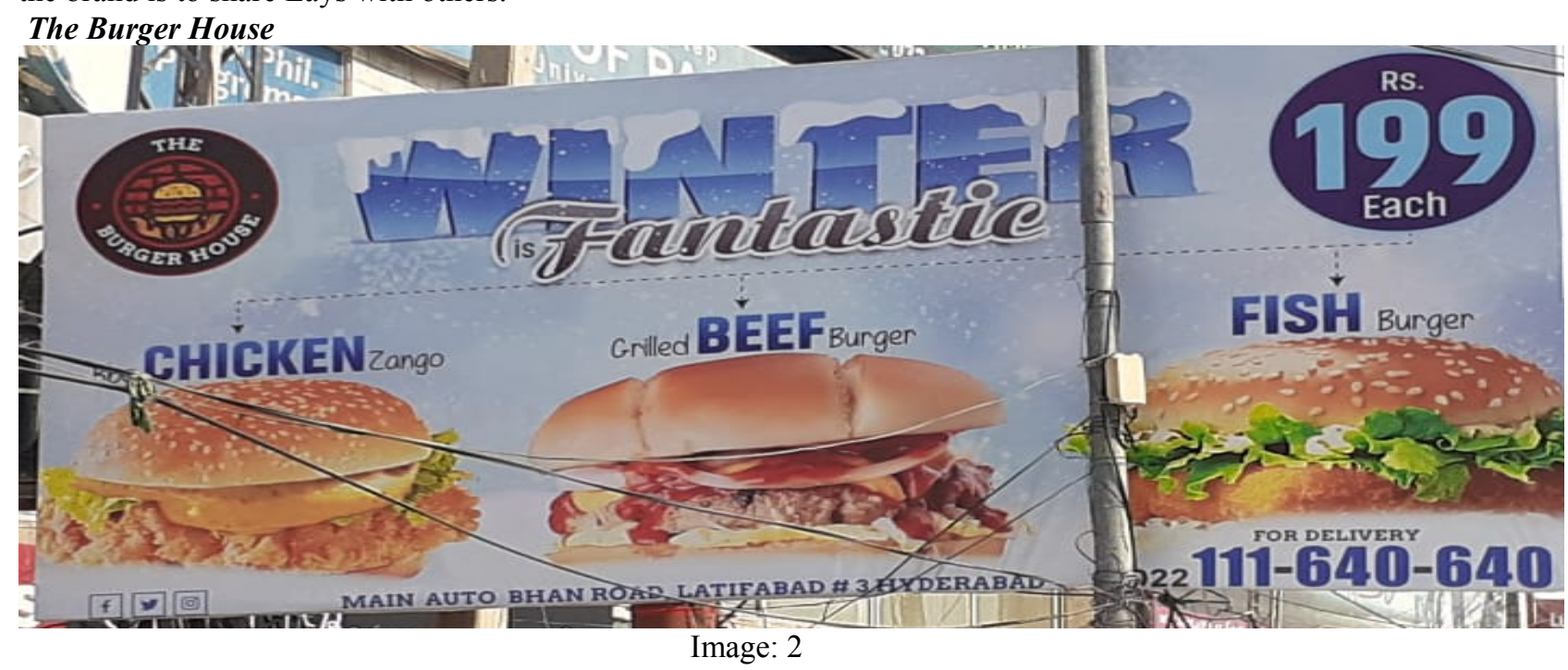

\begin{tabular}{|c|ll|ll|}
\hline SIGN & \multicolumn{1}{|c|}{$1^{\text {st }}$ Order Signification } & \multicolumn{1}{c|}{$2^{\text {nd }}$ Order Signification } \\
\hline Burgers & $\bullet \quad$ Blue Snowy Text & $\bullet$ & Winter season \\
& $\bullet \quad 3$ flavours of burgers & & $\bullet$ Variety of burgers \\
& $\bullet \quad$ Rs. 199 (price) & & $\bullet$ Catchy names for burgers \\
& $\bullet \quad$ Phone number & $\bullet$ & Lower first digit price \\
& & & Home delivery available. \\
\hline
\end{tabular}

Table: 2

\section{Denotation meaning.}

The billboard of the outlet "The Burger House" has portrayed the denotative meaning of winter through their language. The words which are used on the billboard are identified as signifier. The linguistics sign which is used in the billboard is signifying by the only three words, which are "Winter is Fantastic". The product which is shown on the billboard is "Burger". Three burgers are shown on the billboards and the flavours of the burgers are written on the top of the image of the burger. The three varieties of the burgers are recognized as signifier. The brand is offering three flavours which are: chicken, beef and fish. The image of all three burgers are different. These signifiers have different individual units which are indicating to signifier about:

- The linguistics sign which is mentioned on the billboard is "Winter is fantastic", is signifying the claim that winter would be fantastic with their variety of burgers.

- The price $199 \mathrm{Rs}$ is mentioned on the right top of the billboard is signifying the price of one burger.

- The logo of the brand with the colors black and red with yellow burger in it is signifying that the brand only offers burger in their outlet.

- On the right bottom the phone number is written with dark blue color. It signifies that "The Burger House" take home delivery orders.

- $\quad$ On the center bottom of the billboard the address is also mentioned which signifies the location of the billboard.

Connotation Meaning

Barthes is of the view that he sees advertisements under the lens of "how" they are mean instead of "what" 
meaning is attached to them. (cited in Oparinde and Agbede, 2019). The signified meaning of the blue color is the season of the winter. Blue color symbolises the family orientation, original and friendly nature. (Aaker, 1997). The font of the word "winter" in the billboard is designed with snowy letters. The Winter word itself is symbolising the weather but the snow on it is giving signified meaning of peak winter in the city. In addition to that, the dashed line is further connected with 3 burgers and the price of the burgers. The brand has named the burgers with fancy names in order to gain attention of the young people. As the youth mold the language and use catchy terms for various things. Therefore, instead of zinger the brand has named the burger as "chicken zango". The outlet has "beef" and "fish" burgers which are uncommon flavours in the burgers. The pictures of burgers are different from on another, it signifies that a part from meat variety the brand is offering different stuffing also with different burgers.

The connotation of the price which is written on the top right og the billboard is psychological factor. Bauer (2018) is of the view, that the brands use "99" endings in the price of their product is known as "left-digit effect". Bauer stated that the impression of "lower first digit" has a great psychological impression on the buyers. He further added that ending price with "99" digits had a tendency to increase the sale of the product. The contact number on the right bottom of the billboard signifies that the restaurant also facilitates with home delivery orders. On the left bottom of the billboard social media icons are printed which shows that the outlet has the pages on Facebook, Instagram and twitter. It means the buyers can check the deals and updated information about the outlet on the social media handles.

\section{Pizza Track}

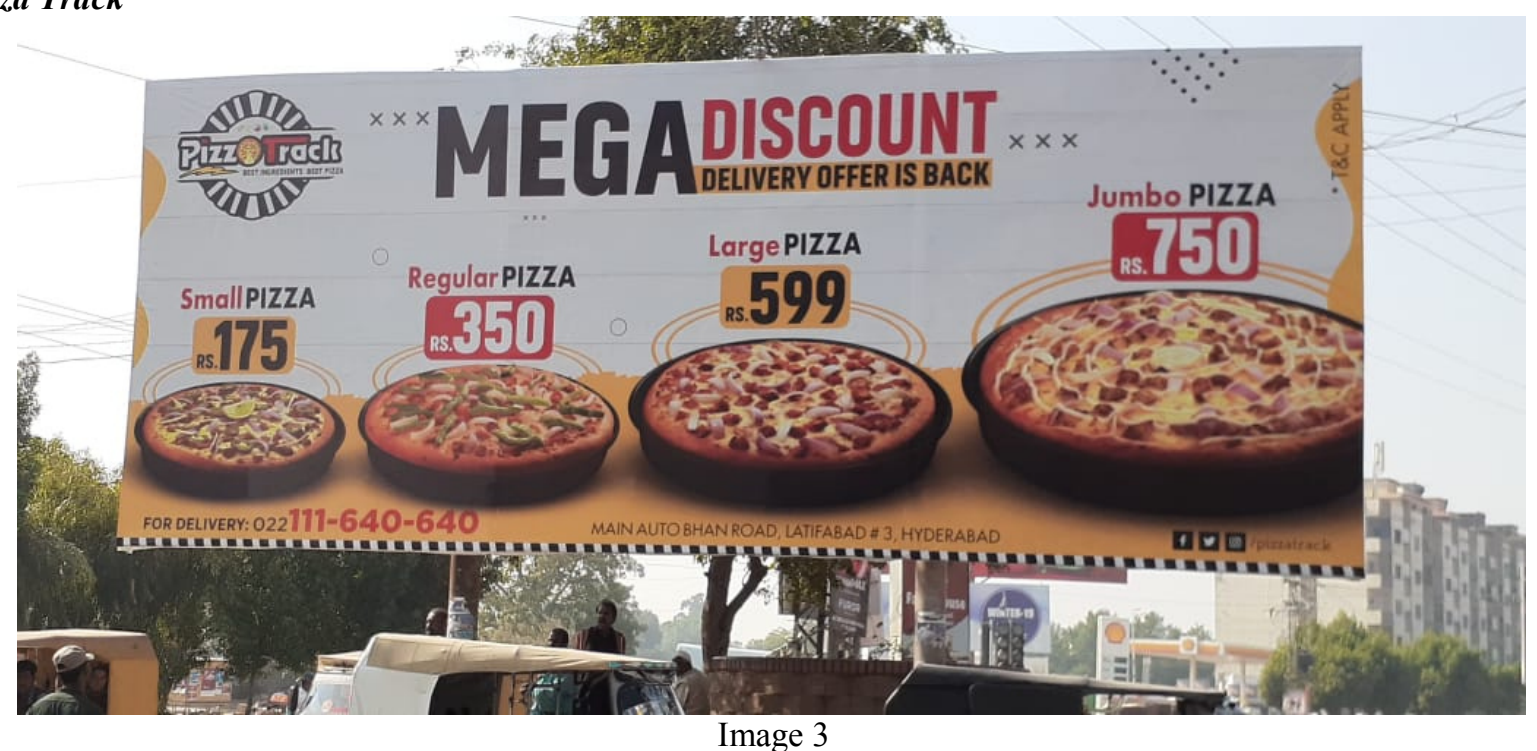

\begin{tabular}{|c|c|c|}
\hline SIGN & $1^{\text {st }}$ Order Signification & $2^{\text {nd }}$ Order Signification \\
\hline $\begin{array}{cc}\text { - } & \text { Pizza } \\
\text { - } & \text { Discount }\end{array}$ & $\begin{array}{l}\text { - "Mega discount, delivery } \\
\text { offer back" } \\
\text { - } \text { Prices of the pizzas } \\
\text { - } \text { Different flavours } \\
\text { - } \text { Phone number } \\
\text { - Colors }\end{array}$ & $\begin{array}{l}\text { - Selling strategy by giving } \\
\text { discount. } \\
\text { - } \quad \text { Highlighting different } \\
\text { prices of the product. } \\
\text { - } \quad \text { Home delivery available. } \\
\text { - } \quad \text { Colors scheme, which } \\
\text { increase hunger. }\end{array}$ \\
\hline
\end{tabular}

Table 3

\section{Denotation meaning}

The signifiers in the billboard of "Pizza track" are highlighted in the form of colors. The brand has used four vivid colors in order to gain attention of the consumers. All four colors have beautified the billboard. The linguistic signs on the image are recognized as signifier. The surface level meaning of the language which is used in the billboard is manipulative. The word "mega" is written with bold, black and capitalized. The second word is followed by $1^{\text {st }}$ word but in the red color "discount". The next linguistics sign on the image is "delivery offer is back". The phrase is written with black color but to gain the attention of the consumers it is highlighted with yellow color.

Further the various prices on the billboard signifies the different pizzas which are portrayed below the mentioned price. The different size of pizzas also signifies the different prices of it. Four different pizzas are 
shown on the image. All four are different in size, flavour and toppings. On the bottom left delivery number is mentioned with the red color along with that address is mentioned on the bottom center of the billboard. The social media handles are also mentioned on the billboard.

\section{Connotation Meaning}

Bathes cited in Boterill et al. (2000) highlights that advertisements try to convince the audiences to use or but the product by adding connotation associations with the product. The color codes in the billboards can be seen are; white, which symbolizes the purity of the product. Red and yellow colors have the association with food industry. According to Brown (2017) red color has the tendency to activate the "appetite" and "hunger". In addition to that, red color grabs the attention of the consumers. On the contrary, yellow color is commonly associated with happiness and friendliness.

According to my life my stuff (2012), black color is a good technical color. It has association with style. Black color with white shows "prudence". The linguistics sign in the billboard is signified by the researcher as thrift. The brand is offering huge discount on the pizzas. The word discount is written with red letters in order to get attention from the audiences

The advertisers have used the strategy of "visually highlight the different prices" in order to signify the prices of the pizzas. Coulter and Coulter (2005) claims that by changing the font, size and color of the products prices which are written in one line affects the minds of the consumers and it helps the consumers to believe that the deal is cheaper to buy. The advertisers on the billboard has used the variety of their pizzas with the various prices, so that the consumers think the lowest price for the pizza is cheapest. And it will lead the buyers to buy the pizza.

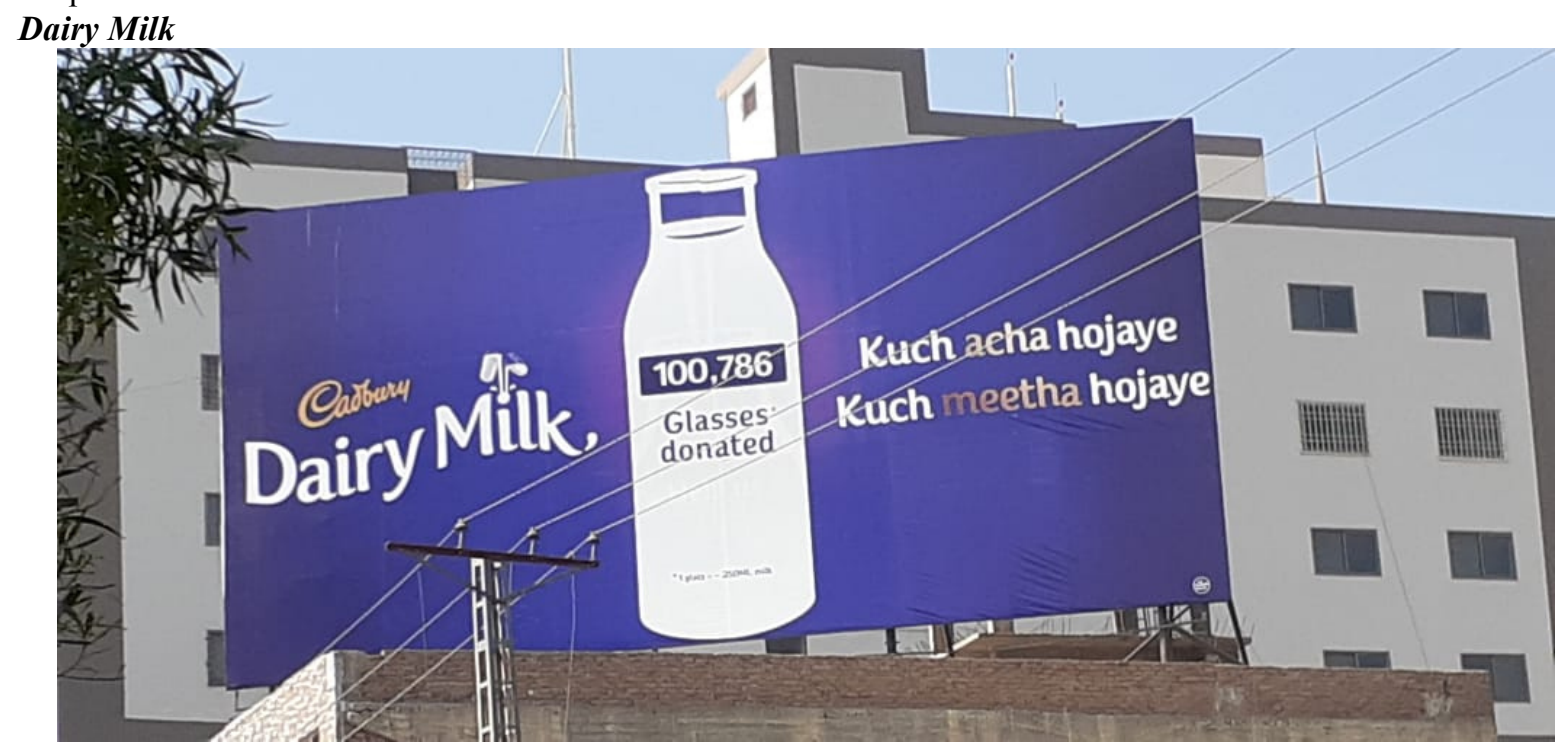

Image 4

\begin{tabular}{|c|c|c|}
\hline SIGN & $1^{\text {st }}$ Order Signification & $2^{\text {nd }}$ Order Signification \\
\hline - Milk bottle & $\begin{array}{ll}\text { - } & \text { Purple color } \\
\text { - } & \text { Milk bottle with } \\
\text { numbers on it } \\
\text { - } \quad \text { Slogan in Roman } \\
\text { Urdu } \\
\text { - Company Name. }\end{array}$ & $\begin{array}{l}\text { - } \quad \text { Trade mark color of the brand } \\
\text { - Milk donation, campaign } \\
\text { - } \quad \text { Numbers shows that many bottles are donated } \\
\text { - Motivating youth and larger audience with } \\
\text { - } \quad \text { Roman Urdu slogan of sharing goodness. } \\
\text { - Iconic writing style of Brand's Name. }\end{array}$ \\
\hline
\end{tabular}

Table 4

\section{Denotation meaning}

Cadbury dairy milk is one of the most desired chocolate in the sub-continent. The billboard shows the bottle of milk with the new slogan "kuch acha hojaye ,kuch meetha hojaye". the slogan is written in roman Urdu. The background of the billboard is purple in color, which is color of the product. The slogan is written in two lines. In both lines the middle word is written in golden and white mix colors rest of the slogan is written in white color. The bottle of the milk is white in color and with the purple background 100,786 is written with white color and on the milk bottle "glasses donated" is written with purple color. On the left of the billboard the name of 
brand is written with the iconic colours golden and white.

\section{Connotation meaning}

The billboard of the dairy milk is of the campaign. The brand initiated the movement for underweighted children in Pakistan. The brand offered a milk bottle distribution on purchase of the chocolate. (ILS MAG, 2020).

Purple color is the trade mark color of the brand Cadbury dairy milk. Cherry (2021) claims that purple color is associated with royalty. It is the color of various feelings. The use of iconic golden color for the company name and middle words in the slogans is symbolising the care and faithfulness of the product. In addition to that, the while color is symbolizing the purity and integrity pf the billboard.

The linguistic sign is written in Roman Urdu. Tellis (2014) claims that Roman Urdu is easy to understand by the audiences therefore the advertisers prefer to use it. the slogan of the dairy milk product is promoting goodness with the sweetness of the chocolate. Act of goodness has been shown by showing the number of milk donations which is written on the billboard. On the bottom of the milk sign, the advertisers have mentioned the size of the milk bottle which is $250 \mathrm{mg}$. The billboard is promoting the motif behind the selling of the chocolate. And people are motivating and participating in the good cause.

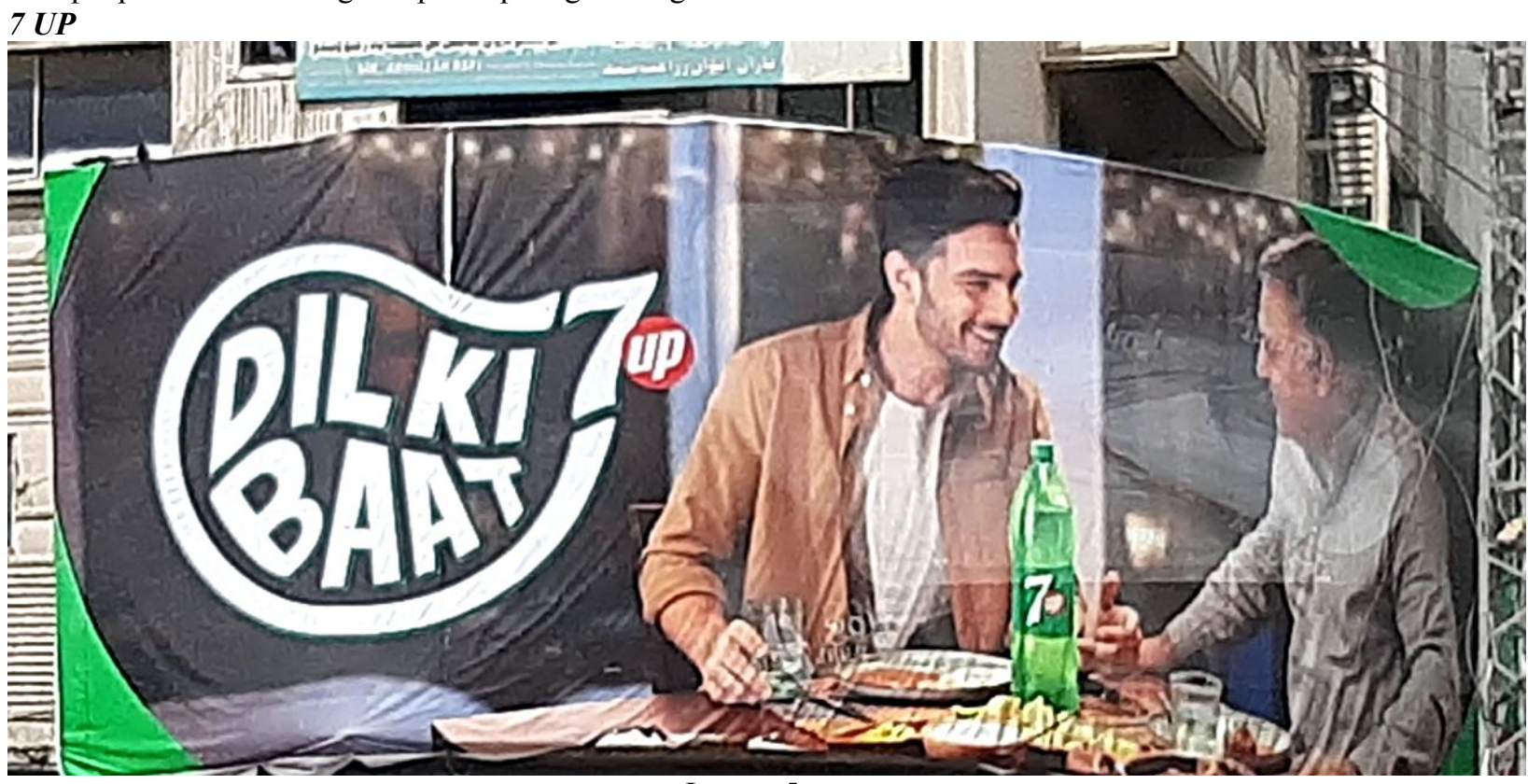

Image: 5

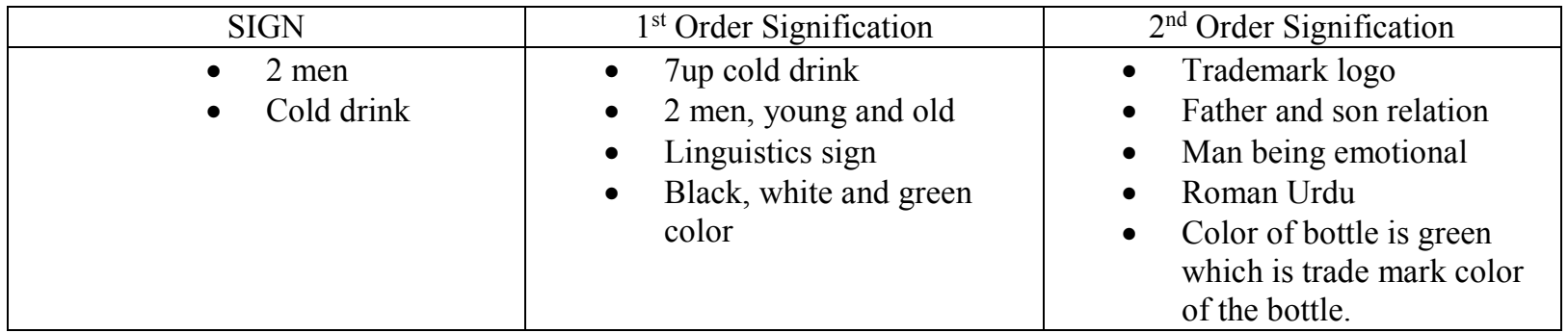

Table 5

\section{Denotation Meaning}

The above billboard is of the well-known cold drink 7up. In the billboard two men are shown one is old and other is young. Both are talking to each other. The bottle of 7 up is clearly shown in the image. However, the other food is blur. The background of the billboard is black in color. The linguistics sign on billboard is limited to only 3 words with the brand name which is written in white color. The trade mark name of the product is seen clearly on the billboard. The corners of the billboard are green in color.

\section{Connotation Meaning}

The billboard of 7up is from the Ramadan edition. The Ramadan is the holy month of the Muslims, in which Muslims fast and observe spiritual deeds specially in this month. The essence of Ramadan is shown in the picture in which the brand has added the slogan of "Dil ki Baat" in which the motto of emotions is shown in the 
billboard.

The billboard has two actors from Pakistan Industry, one is representing the role of son while other is representing the father. Men in every society are considered to be emotionless and this image of the man can be seen in various advertisements and media industry. Fisher and Dube (2005) cited Broverman et.al (1972), asserts that the men are hesitant to show their deep-seated emotions and particularly the feelings which are associated with fragility, reliance and powerlessness. However, this billboard is breaking the stereotype of the "Manly man" and promoting the father son bond with intimacy of father son love. In the billboard, the researcher has analysed that the emotions are clearly seen through the faces of the actors who seems to enjoy their time with the cold drink. Moreover, the linguistic sign "dil ki baat" is connotating to let go the bottle up emotions and say it all.

The colors of the billboard are carefully selected, the cold drink is green in color which is vividly seen in the billboard. The other food items on the table are blur, cannot seen properly because the major focus of the billboard is on its product. The black color is showing the comfort and protection of the bond which is shown in the billboard. The iconic green color of the corners in the billboard are supporting the brand's color which is green itself.

\section{Cricket Combo}

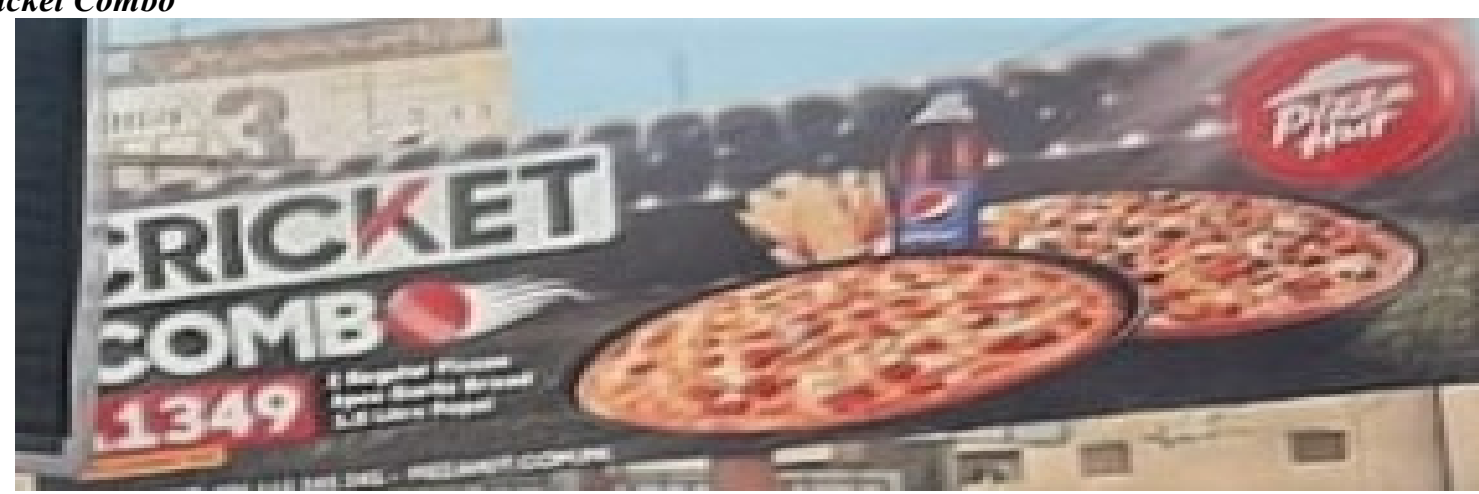

Image 6

\begin{tabular}{|c|c|c|}
\hline SIGN & $1^{\text {st }}$ Order Signification & $2^{\text {nd }}$ Order Signification \\
\hline $\begin{array}{ll}\text { - } & 2 \text { Pizza } \\
\text { - } & \text { Pepsi } \\
\text { - } & \text { Ball }\end{array}$ & $\begin{array}{ll}\text { - } & \text { Cricket offer } \\
- & 2 \text { pizzas with garlic bread } \\
& \text { and Pepsi } \\
\text { - } & \text { Price. }\end{array}$ & 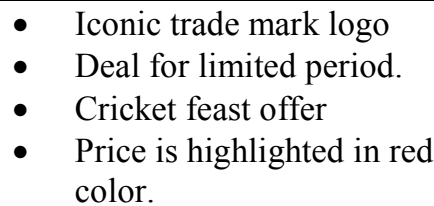 \\
\hline
\end{tabular}

Table 6

\section{Denotation Meaning}

Pizza Hut is one of the oldest stores that serves Pizza in Pakistan. The logo of the Pizza Hut is printed in red and white color with white hat on it. The billboard shows 2 Pizzas with a cold drink Pepsi and Garlic bread. The background of the billboard is signifying cricket stadium and the linguistic on the billboard is written with white and black combination, the text says: "Cricket combo" with the symbol of ball on it. The price of the deal is mention with white color and red background the price is "Rs. 1349", the further information clarifies that the brand is offering 2 regular pizzas with 4 pcs of garlic bread and 1.5-liter Pepsi.

\section{Connotation meaning.}

The fast food chain is offering the cricket deal to the consumers. The cricket in Pakistan is not only a sport but it connects people together. Coakley (2004) believes that cricket in Pakistan and India is not only a sport but it shapes identity, connections and it works as unified force for the masses.

The background of the billboard is signified as the cricket stadium, which symbolises the eve of cricket. The brand is offering the deal for people who loves cricket to watch. Deal is for more than two people. It offers two Pizzas, one cold drink Pepsi and 4 pcs of garlic bread. For the information the brand has used triple color effect. Three colors are used on the billboard to share the information about the deal which are; red, black and white. Inoman (2019) is of the view that in terms of advertising, red color is used to show that offer is for limited period. Red color prioritizes the product and it bound the consumers to buy the deal. The term "Cricket Combo", symbolizes that the deal is offered only during cricket season. The price for the deal is 1349 Rs. Which is written in bold white numbers with red background. 


\section{CONCLUSION}

This study deals with the analysis of 6 food and beverages billboards. The study is conducted in the context of Hyderabad, Sindh. Qualitative methodology has been used to analyze the billboards. The researcher implied the theory of Roland Barthes 'semiology in order to analyze the billboards. Three codes have been considered in terms of analysis. The results show that the billboards of food and beverages has played with different colors in order to manipulate the costumers. The advertisers used the colors which enhances hunger among the audiences. The advertisers also used colors which have high wave length so that viewers can see the billboard from the distance. Along with that in terms of linguistics sign the researcher has analysed that advertisers have used various techniques from code switching to used of English which is found very common in the billboards. The use of Roman Urdu is also seen in the billboards. The advertisers have used the cultural, symbolic and semantic codes in the billboards so that the audiences can buy their products.

\section{References}

Aaker, J. (1997). Dimensions Of Brand Personality. Journal Of Marketing Research, 34(3), $347-356$. Doi: $10.2307 / 3151897$

Baurer.C (2018) "Why Prices End In 99... And Other Psychological Pricing Tactics" Retrieved From: Https:/Www.Simon-Kucher.Com/En/Blog/Why-Prices-End-99-And-Other-Psychological-Pricing-Tactics

Bignell, J. (2002). Media Semiotics: An Introduction. Manchester New York: Manchester University Press

Botterill, Jackie, Iain MacRury, Barry Richards (2000). The Dynamics of Advertising. London: Routledge.

Brown.J (2017) “The Surprising Reason Why The Mcdonald's Sign Is Red And Yellow" Retrieved From Https:/Www.Indy100.Com/Discover/Mcdonalds-Brand-Signs-Yellow-Red-Psychology-Calming-Hungry7944036

Cherry.K (2021) The Color Psychology Of Purple Retrieved From Https:/Www.Verywellmind.Com/The-ColorPsychology-Of-Purple-2795820

Coakley, J. (2004). Sports in Society: Issues and Controversies (Eleventh Edition). Revija Za Sociologiju, 45(2), $35-45$.

Cook, G. (2001). The Discourse of Advertising. London And New York: Routledge.

Adams,Y., Matu.P., \& Oketch, O. (2014). Multimodality In Safaricon Advertisement

Communication In The Kenyan Daily Nation Newspaper. Academic Journal Of Interdisciplinary Studies, 3(6), Pp.403-410. Doi:10.5901/Ajis.2014,V3n6p403.

Coulter, K. S., \& Coulter, R. A. (2005). Size Does Matter: The Effects Of Magnitude Representation Congruency On Price Perceptions And Purchase Likelihood. Journal Of Consumer Psychology, 15(1), 6476.

da Silva, A. M. (2017). A Semiotic study of one ready-to-drink tea billboard advertisement in Jakarta. Lingua Cultura, 11(2), 73-77.

Dunbar, R.I.M. Breaking Bread: The Functions Of Social Eating. Adaptive Human Behavior And Physiology 3, 198-211 (2017). Https://Doi.Org/10.1007/S40750-017-0061-4

Fisher, R., Dubé, L., \& [Dawn Iacobucci Served As Editor And Gene Anderson Served As Associate Editor For This Article.]. (2005). Gender Differences In Responses To Emotional Advertising: A Social Desirability Perspective. Journal Of Consumer Research, 31(4), 850-858. Doi:10.1086/426621

Fiske,John cultural and communication studies, Yogyakarta JALASUTRA, 2007

Ils Mag, (2020). Cadbury Dairy Milk's Movement For Under-Weight Children In Pakistan Retrieved From Https://lsmag.Com.Pk/News/Cadbury-Dairy-Milks-Movement-For-Under-Weight-Children-In-Pakistan/

Inoman (2019) The Psychological Impact Of Billboard Advertising Retreieved From Https://75media.Co.Uk/Blog/Psychological-Billboard-Advertising/

Ma'rifah, U. (2020). How Children Perceive Food Advertisements On Tv: A Semiotics Analysis. Didaktika : Jurnal Pemikiran Pendidikan, 26(1), 49-59. Doi:10.30587/Didaktika.V26i1.1465

Mylifemystuff (2012) Emotional And Psychological Meaning Of Colours Retrieved From: Https://Mylifemystuff.Wordpress.Com/2012/04/26/Emotional-And-Psychological-Meaning-Of-Colours/

Nassaji, H. (2015). Qualitative and descriptive research: Data type versus data analysis.

Ridho, A., Yanti, Y., \& Rina, (2019). An Analysis Of Implicature Used In Cigarettes 'slogan Found On The Billboards.

Oparinde, K. M., \& Agbede, G. T. (2019). Visual Hyperbolism: A Semiotic Analysis of Fast Food Advertisements in South Africa. Interdisciplinary Journal of Economics and Business Law, 8, 369-391.

Pramudita, I. N., Susilo, M. E., \& Rohayanti, C. (2019). Analysis Of Signs And Meanings In Sariayu Hijab Haircare Advertisements (Semiotic Analysis Of Instagram Account@ Sariayuhijab). The Indonesian Journal Of Communication Studies, 10(2), 94-107.

Singh, S. (2006). Impact Of Color On Marketing. Management Decision.

Tellis.T. (2014). Ki Or Key? Hai Or Hay? Retrieved From Https://Aurora.Dawn.Com/News/1140930 
Wibowo, A. A., \& Ardhianto, P. (2020). Iconology Analysis In Advertising Design, Case Study Go-Jek Billboard Advertising: Series" Mager Tanpa Laper" In Yogyakarta-Indonesia. International Journal of Visual And Performing Arts, 2(1), 8-14. 